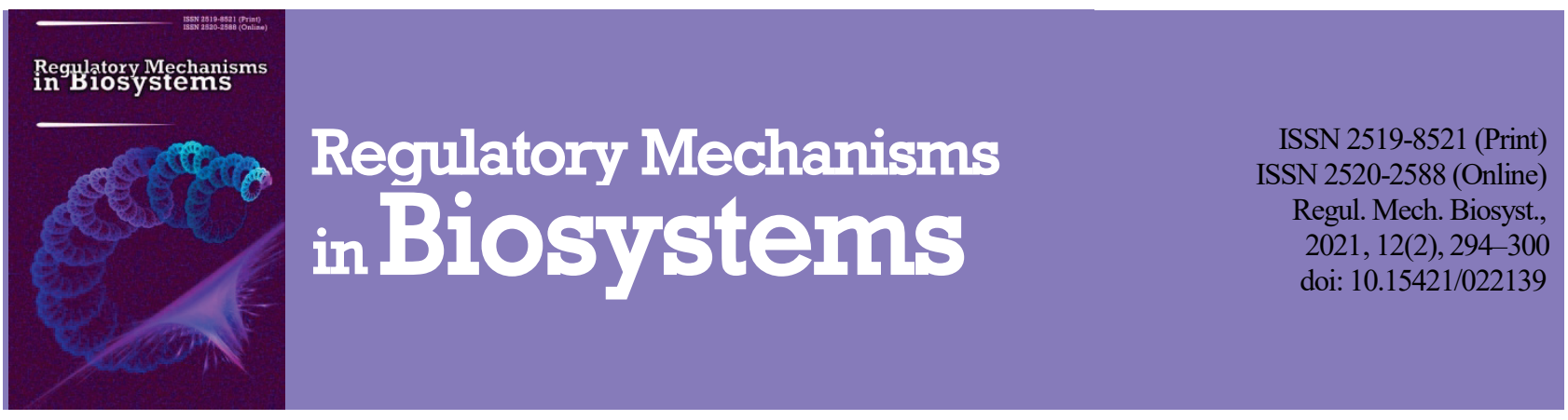

\title{
Morphogenesis, pigment content, phytohormones and productivity of sweet pepper under the action of gibberellin and tebuconazole
}

\author{
V. V. Rogach*, V. G. Kuryata*, I. V. Kosakivska**, L. V. Voitenko**, M. M. Shcherbatiuk**, T. I. Rogach* \\ *Vinnytsia Mykhailo Kotsiubynskyi State Pedagogical University, Vinnytsia, Ukraine \\ **M. G. Kholodny Institute of Botany, National Academy of Sciences of Ukraine, Kyiv, Ukraine
}

Article info

Received 23.03.2021

Received in revised form 26.04.2021

Accepted 27.04.2021

Vinnytsia Mykhailo Kotsiubynskyi State Pedagogical University,

Ostrozhskogo st., 32, Vinnytsia, 21000, Ukraine. Tel.: +38-098-59-44-832. E-mail:rogach@@ukr.net

M. G. Kholodny Institute of Botany, National Academy of Sciences of Ukraine,

Tereshchenkivska st., 2 Kyiv, 01004, Ukraine Tel.: +38-097-23-86-757. E-mail:

lesyavoytenko@gmail.com

\begin{abstract}
Rogach, V. V., Kuryata, V. G., Kosakivska, I. V., Voitenko, L. V., Shcherbatiuk, M. M., \& Rogach, T. I. (2021). Morphogenesis, pigment content, phytohormones and productivity of sweet pepper under the action of gibberellin and tebuconazole. Regulatory Mechanisms in Biosystems, 12(2), 294-301. doi:10.15421/022139
\end{abstract}

\begin{abstract}
One of the main tasks of modern plant physiology is regulation of growth and development of cultivated plants in order to optimize the productive process. The attention of the scientific community is focused on the use of natural activators and growth inhibitors. We investigated the effect of foliar treatment with $0.005 \%$ solution of gibberellic acid (GA3) and $0.025 \%$ solution of the antigibberellic preparation tebuconazole (EW-250) on morphogenesis, leaf mesostructure, the content of photosynthetic pigments, the balance of endogenous phytohormones and productivity of Capsicum annum L., Antey variety. The vegetation experiment was carried out in the conditions of soil-sand culture in vessels with a volume of $10 \mathrm{~L}$. Treatment of plants was carried out in the budding phase. Morphometric parameters were determined every 10 days. The mesostructure of the middle tier leaves was studied in the fruit formation phase, and the chlorophyll content was determined in the raw material by spectrophotometric method. Analytical determination of endogenous phytohormones - indolyl-3-acetic (IAA), gibberellic (GA3) and abscisic (ABA) acids and cytokinins - zeatin (Z), zeatin-O-glucoside (ZG), zeatinribozide (ZR), isopentenyladenine (iP) and isopentenyladenosine (iPA) were performed by high performance liquid chromatography - mass spectrometry (HPLC-MS). With GA3 treatment, plant height increased considerably, while with EW-250, it decreased. Both regulators led to an increase in the number of leaves on the plant, the leaf raw biomass, stems and roots and the dry matter of the whole plant, the area of a single leaf blade and the total area of leaves on the plant. Under the action of EW-250, the chlorophyll content in the leaves surged, while under the action of GA3 it tended to decrease or did not change at all. Both regulators thickened the chlorenchyma and boosted the volume of the columnar parenchyma cells. GA3 treatment induced a rise in the thickness of the upper and lower epidermis, and EW-250 led, on the contrary, to a decrease. It is shown that after treatment with exogenous GA3, the content of endogenous IAA and ABA decreased and GA3 in plant stems increased. Instead, EW-250 caused a decrease in the levels of GA3, IAA and ABA in the stems. Exogenous GA3 enhanced the accumulation of endogenous GA3 and IAA and inhibited ABA in the leaves. Under the action of the retardant, the level of ABA in the leaves did not change, while GA3 and IAA decreased. Treatment of plants with the studied growth regulators caused a decrease in the pool of cytokinins (CK) in stems. EW-250 showed a significant rise in the hormone content in the leaves. After spraying with GA3 solution, the level of ZG, Z and ZR grew. Under the action of the retardant, the increase in the CK pool occurred exclusively due to the iP. Growth regulators optimized the productivity of sweet pepper plants: under the action of GA3 there was an increase in the number of fruits per plant, and after the use of EW-250 there was a rise in the average weight of one fruit. The obtained results showed that anatomical-morphological and structural-functional rearrangements of sweet pepper plants under the action of exogenous gibberellic acid and EW-250 took place against the background of changes in the balance and distribution of endogenous hormones. Increased photosynthetic activity, stimulation of growth processes of some plant organs and inhibition of others enlarged biological productivity of the culture.
\end{abstract}

Keywords: Capsicum annuum; growth stimulants; growth inhibitors; morphometry; leaf apparatus; plant hormones; crop capacity.

\section{Introduction}

Development of methods and technologies that would ensure a fuller use of light energy by the plant to intensify the synthesis of assimilates is an important task of modern phytophysiology, which can lead to metabolic disorders in animals consuming plant products (Lieshchova et al., 2018; Kozak et al., 2020). One of the key approaches in solving the issue of optimizing the production process of agricultural plants is the regulation of donor-acceptor relations, in particular by artificial redistribution of assimilate flows to fruits, roots and other storage organs (Khodanitska et al., 2019; Poprotska et al., 2019). The main patterns of functioning of donor-acceptor relations (the concept of "source-sink") are studied mainly in the analysis of the ratio of intensity of growth processes and photosynthesis, where growth processes act as the main acceptor, and photosynthesis - as a donor of assimilates (Yu et al., 2015; Poprotska et al., 2019).
Use of native phytohormones and synthetic growth regulators, which by their nature are either analogues or modifiers of phytohormones, is a promising area of artificial regulation of growth processes. Growth, development and productivity of plants are known to be under hormonal control (Rademacher, 2016). Phytohormones which regulate linear shoot growth and cell stretching, enhance the activity of intercalary meristems, delay leaf aging, and stimulate flowering and fruiting are grouped into the gibberellic family (Rademacher, 2016). Today there are about 150 forms of gibberellic-like substances, among which the most active from a physiological point of view and the most used in basic and instrumental research and agricultural practice are GA1, GA3, GA4, GA7, GA9 and GA20. A classic representative of gibberellins, which has become widely used, is gibberellic acid (GA3).

Exogenous use of this native phytohormone significantly affects the entire hormonal complex of plants. In particular, treatment of sugar cane 
seedlings with exogenous GA3 increased the content of IAA and decreased ABA, but did not affect the content of cytokinins (Qiu et al., 2019). Priming the grains of two varieties of winter wheat with GA3 solutions at concentrations of 100,150 and $200 \mathrm{mg} / \mathrm{L}$ considerably reduced the levels of ABA and IAA in the leaves (Muhammad \& Muhammad, 2013). The use of the same preparation on plants of Polygonum cuspidatum boosted the content of gibberellins and cytokinins (Sugiura et al., 2015). Soaking cucumber seeds in aqueous solutions of GA3 at doses of $1,30,45$ and $60 \mu \mathrm{mol} / \mathrm{L}$ caused the accumulation of endogenous GA3 and IAA in the leaves, the maximum of which occurred during flowering and fruiting (Ullah et al., 2011). GA3 at concentrations of 100, 200 and $300 \mathrm{mg} / \mathrm{L}$ increased the content of endogenous GA3 and IAA in the first and sixth leaves of camellia (Wen et al., 2018). Inoculation of soybeans with rhizobacteria led to extended secretion of GA1, GA4, GA9 and GA20, which contributed to an increase in endogenous GA3 and a decrease in ABA (Kang et al., 2014). We found that pre-treatment of plants in the budding phase of exogenous GA3 caused a rise in the content of endogenous GA3, IAA and ABA in the leaves and stems of eggplant (Rogach et al., 2020). Native gibberellin-like compounds and their synthetic analogues are actively used in crop production to intensify histo- and morphogenesis, accelerate cell proliferation and differentiation, resulting in the formation of a more branched root system, they strengthen the leaf apparatus, which can provide active synthesis of plastic compounds and storage bodies. Thus, the enhanced synthesis of GA1, GA4, GA9 and GA20 by rhizobacteria enlarged the linear size of soybean plants, the mass of dry and raw matter of shoots and the content of chlorophyll in the leaves (Kang et al., 2014). An increase in plant height due to elongation of the internode was recorded in sugar cane (Qiu et al., 2019). Similar morphometric effects, as well as a rise in the rate of photosynthetic processes, respiratory conductivity and transpiration rate, were observed with the use of exogenous GA3 at concentrations of 100, 150 and $200 \mathrm{mg} / \mathrm{L}$ (Muhammad \& Muhammad, 2013). In Polygonum cuspidatum plants, the preparation increased the mass of raw matter of leaves and the rate of photosynthesis and carbon dioxide absorption, but decreased the leaf index (Sugiura et al., 2015), while in cucumber plants the leaf index was boosted significantly (Ullah et al., 2011). Treatment of camellia with GA3 at doses of 100, 200 and $300 \mathrm{mg} / \mathrm{L}$ increased the content of chlorophyll in the leaves, its fluorescence parameters and the rate of photosynthesis (Wen et al., 2018). We have shown that GA3 enlarged potato plant height, leaf weight and leaf dry matter, leaf surface index, leaf area and thickening due to better chlorenchyma development, which enlarged the volume of columnar parenchyma cells and the size of spongy parenchyma cells. The stimulant increased the net productivity of photosynthesis and the dry matter mass of the whole plant. Exogenous use of phytohormone increased tuber yield (Rohach et al., 2020). An increase in linear size, leaf mass, leaf surface index, leaf area and net photosynthesis productivity after application of GA3 was also recorded in eggplant plants (Rohach, 2017).

Anti-gibberellic preparations are widely used in crop production. In particular, onium, triazole and pentanol derivatives of isobutyrates and prohexadions that block the synthesis of gibberellins (Ribeiro et al., 2012; Polyvanyi et al., 2020; Shevchuk et al., 2020) as well as hydrazine derivatives and ethylene producers that prevent the hormone from binding to the receptor protein (Shevchuk et al., 2019). This leads to changes in hormonal status, causes anatomical and morphological and physiological and biochemical changes.

Triazole derivatives are characterized by exceptionally high antigibberellic activity. Their effect on the growth of axial organs of plants is associated with inhibition of ent-kaurensintetase activity and inhibition of the conversion of geranylgeranioldiphosphate to copalylpyrophosphate and further to ent-kauren (Radamacher, 2016). Triazole derivatives inhibit the conversion of ent-kauren to kaurenic acid, reduce the activity of $\alpha$-amylase (Radamacher, 2016). Under the action of triazole and pentanol derivatives, the whole complex of phytohormones undergoes significant changes (Soumya et al., 2017).

Paclobutrazol is one of the first studied and widely used triazole derivatives. In particular, the use of paclobutrazol at a dose of $300 \mathrm{mg} / \mathrm{L}$ reduced the content of gibberellins and increased IAA and ABA in lily plants (Zheng et al., 2012; Ahmad et al., 2019). In contrast, paclobutrazole at a concentration of $50 \mathrm{mg} / \mathrm{L}$ reduced the content of gibberellins in radish leaves (Jabir et al., 2017) and in flax plants (Kim et al., 2018) to trace concentrations. Application of paclobutrazol in the amount of $3 \mathrm{~mL} / \mathrm{m}$ of mango crown diameter increased the content of $\mathrm{ABA}$ and cytokinins $(\mathrm{Z}$, $\mathrm{ZR}$ and dihydrozeatinriboside) in the buds until the beginning of flowering and decreased the content of GA1, GA3, GA4 and GA7. A fall in the latter is also recorded in the leaves of this culture (Upreti et al., 2013). This preparation at a dose of $1 \mathrm{~g} / \mathrm{m}^{2}$ crown inhibited the synthesis of GA1, GA3 and GA4 in mango plants (Cavalcante et al., 2020). Medium and high concentrations of paclobutrazol decreased the content of GA3 and IAA and increased the content of ABA in magnolia leaves. The decrease in GA3 content was clearly correlated with the rise in ABA content (Shi et al., 2021). We found out that EW-250 reduced the content of endogenous GA3, IAA and increased ABA in eggplant leaves and stems during processing in the budding phase (Rogach et al., 2020).

Uniconazole is one of the most active antigiberellins. Foliar treatment of Landoltia punctata L. with uniconazole at a dose of $800 \mathrm{~m} / \mathrm{L}$ enlarged the content of ZR and ABA and decreased the content of GA1, GA3, GA4 and GA7 (Liu et al., 2015). The use of triazole on barley plantations increased the content of $\mathrm{ABA}$ and the amount of cytokinins in the leaves and decreased GA3 and IAA (Bakheta \& Hussein, 2014). The content of gibberellins diminished under the action of uniconazole in plants of Polygonum cuspidatum (Sugiura et al., 2015). High and medium doses of the preparation boosted the content of $\mathrm{ABA}$ and decreased the content of GA3 and IAA in the leaves of magnolia plants. The increase in ABA content was clearly correlated with a fall in the amount of GA3 (Shi et al., 2021). Rapeseed plants were treated with uniconazole at doses of $0.5,1.0$, 1.5 and $2.0 \mathrm{mg} / \mathrm{L}$, which led to a fall in GA3 and IAA and a rise in cytokinins and ABA in roots and shoots (Zuo et al., 2020). Another triazolederived inhibitor of gibberellin, hexaconazole, at a dose of $100 \mathrm{ppm}$, almost doubled the ABA content in cucumber leaves (Tae-Yun \& JungHee, 2012)

Restructuring of the hormonal complex under the influence of retardants and the corresponding inhibition of apical dominance led to important, in terms of regulation of plant productivity, strengthening of stem branching, which led to the laying of more leaves, flowers and fruits, which is an important prerequisite for improved yields. In particular, paclobutrazol at concentrations of 40,80 and $160 \mathrm{ppm}$ inhibited linear growth and enhanced stem branching in flaxseed (Kim et al., 2018). Paclobutrazol increased the chlorophyll content of lily leaves due to chlorophyll and enhanced the transport and utilization of photoassimilates (Zheng et al., 2012; Ahmad et al., 2019). The same preparation at a dose of $50 \mathrm{~g} / \mathrm{L}$ increased the a rate of photosynthetic processes in radish plants (Jabir et al., 2017). Application of paclobutrazole to the soil at a dose of $3 \mathrm{~mL} / \mathrm{m}^{2}$ of crown increased the diameter of the crown and the amount and weight of crude mango leaves (Upreti et al., 2013).

Foliar treatment of Landoltia punctata L. with uniconazole increased the amount of chlorophyll in the leaves and accelerated photosynthetic processes (Liu et al., 2015). An increase in the rate of photosynthesis and enlarged $\mathrm{CO}_{2}$ absorption was observed under the action of the same preparation in plants of Polygonum cuspidatum (Sugiura et al., 2015). Uniconazole in all applied concentrations reduced the height of magnolia plants by shortening the internodes, did not affect the diameter of the stem and reduced the number of nodes on the plant (Shi et al., 2021). The use of uniconazole in doses of $0.5,1.0,1.5$ and $2.0 \mathrm{mg} / \mathrm{L}$ caused a decrease in the linear size of the stem and its thickening in rapeseed plants in direct proportion to the dose of the preparation. The retardant enlarged leaf area and mass of shoot and root dry matter in low and medium concentrations (Zuo et al., 2020). Treatment of cucumber plants with hexaconazole at a dose of $100 \mathrm{ppm}$ reduced the linear size of plants, reduced the weight of raw and dry matter of stems and leaves, leaf area, but thickened stems and leaves. Under the influence of the preparations, the content of chlorophyll in the leaves rose due to chlorophyll and the level of chlorophyll fluorescence increased (Tae-Yun \& Jung-Hee, 2012).

Thus, the numerical data of the scientific literature show that the exogenous use of gibberellins and also their most active antagonists - retardants from the group of triazoles, often leads to the same result - optimization of the production process of crops and increase in their yield. However, in the literature there are almost no comparative systematic studies of the regulation of growth rate, morphogenesis, formation of the photosyn- 
thetic apparatus and hormonal status of plants of vegetable nightshade crops under the action of GA3 and triazole-derived retardants. Also, the components of the system of regulation of donor-acceptor relations in plants under the action of these preparations remain unknown.

In connection with the abovementioned, the aim of the study was to study the effect of exogenous growth regulators - gibberellin and tebuconazole on morphogenesis, content of photosynthetic pigments, balance of endogenous phytohormones and productivity of sweet pepper Capsicum annuиm L. and determine the role of morphological, mesostructural and hormonal components in the regulation of donor-acceptor relations.

\section{Materials and methods}

A vegetation experiment was laid in the conditions of soil-sand culture in opaque plastic vessels with a capacity of 10 liters. Grey forest podzolic coarse-dusty-medium loamy soil in a mixture with sand in a ratio of 3:1 was used. Plants were grown under controlled conditions at a temperature of $+20 / 17^{\circ} \mathrm{C}$ (day/night), light intensity $190 \mu \mathrm{mol} /\left(\mathrm{m}^{2} \cdot \mathrm{s}\right)$, photoperiod $16 / 8$ hours (day/night), relative humidity $-65 \pm 5 \%$, the humidity of the substrate was maintained at $60 \%$ of total moisture content. They were watered daily with Knop's solution at the rate of $250 \mathrm{~mL}$ per vessel.

Sweet pepper plants of Antey variety in the budding phase were treated once until the leaves were completely wetted with $0.005 \%$ solution of gibberellic acid (GA3) (Power Grown, USA) and a $0.025 \%$ solution of tebuconazole (EW-250) (Bayer, Germany). Control plants were treated with distilled water. The repetition of the vegetation experiment is tenfold.

Analysis of morphological parameters was performed every 10 days from the date of treatment. To determine the mass of individual organs, they were weighed on laboratory scales. The area of the leaves was determined by the method of felling (Latimer, 2012). The average area of the leaf blades was determined by multiplying the length of the leaf blade by its width and by a conversion factor of 0.75 .

The leaf mesostructure was analyzed during carpogenesis (30th day after treatment). For anatomical analysis, the leaves of the middle tier were selected, which had completely finished growing. The plant material was stored in a mixture of equal parts of ethyl alcohol, glycerin, water with the addition of $1 \%$ formalin. The size of individual cells of chlorenchyma was determined in the preparations obtained by partial maceration of leaf tissues. The macerating agent was a $5 \%$ solution of acetic acid in hydrochloric acid $(2 \mathrm{~mol} / \mathrm{L})$. The dimensions of the anatomical elements were determined on a microscope Mikmed-1 (Lomo-Microsystems, RF) using an ocular micrometer MOV-1-15× (Lomo-Microsystems, RF). Microscopic measurements were repeated thirty-five times.

The chlorophyll content was determined in the raw material by spectrophotometric method on a spectrophotometer SF-16 (RF). The experiment was repeated five times (Latimer, 2012).

To determine phytohormones, a portion of the material $(2 \mathrm{~g})$ was triturated in liquid nitrogen and homogenized in $10 \mathrm{~mL}$ of extraction solution (methanol, water, formic acid in a ratio of 15:4:1) and extracted for 24 hours. The extracts were centrifuged for 30 minutes at $15,000 \mathrm{rpm}$ at a temperature of $+4{ }^{\circ} \mathrm{C}$ in a K-24 centrifuge (Janetski, Germany). The supernatants were drained, and $5 \mathrm{~mL}$ of extraction solution was added to the precipitate and kept for another 30 minutes, after which it was centrifuged again. The combined supernatants were evaporated to $5 \mathrm{~mL}$ using a Typ $350 \mathrm{P}$ vacuum evaporator (Poland). Further purification of phytohormones was performed by the method (Kosakivska et al., 2020) on two solidphase columns SPE C18, Sep-Pak Plus, Waters and SPE Oasis MCX, $6 \mathrm{cc} / 150 \mathrm{mg}$, Waters. Column C18 was used to remove lipophilic substances, proteins and pigments. The SPE Oasis MCX column was sorbed with IAA, ABA, GA3 and cytokinins. Elution of IAA, ABA, GA3 was performed with $100 \%$ methanol, cytokinins - with alkaline eluent: $60 \mathrm{~mL}$ of $100 \%$ methanol and $2.5 \mathrm{~mL}$ of $26 \%$ ammonia were adjusted with ultrapure water to a volume of $100 \mathrm{~mL}$. The obtained eluent was evaporated to dryness on a vacuum rotary evaporator at a temperature not exceeding $+40{ }^{\circ} \mathrm{C}$. The dry residue of each fraction was reduced to $200 \mu \mathrm{L}$ with $45 \%$ methanol before analysis.

Analytical determination of phytohormones was performed by high performance liquid chromatography on Agilent 1200 LC liquid chromatograph with diode-matrix detector G $1315 \mathrm{~V}$ (USA) in tandem with a single-quadrupole mass spectrometer Agilent G6120A. An Agilent Zorbax Eclipse Plus $\mathrm{C} 18$ column with a lipophilic-modified sorbent with a particle size of $5 \mu \mathrm{m}$ (reverse phase chromatography) was used for chromatographic separation. After chromatographic separation of the components of the samples with a volume of $20 \mu \mathrm{L}$ by a solvent system of methanol, ultrapure water, acetic acid in a volume ratio of 45:54.9:0.1, we performed the detection of IAA and ABA in the UV absorption region at analytical wavelengths 280 and $254 \mathrm{~nm}$. After separating the samples with a solvent system, acetonitrile, ultrapure water, acetic acid (30:69.9:0.1) we detected GA3 on the signal of the mass detector. Samples with cytokinins were separated by a solvent system of methanol, water, acetic acid (35:64.5:0.5), and detection was performed at $269 \mathrm{~nm}$. The rate of the mobile phase of solvents during the detection of IAA and ABA was $0.7 \mathrm{~mL} / \mathrm{min}, \mathrm{GA} 3$ and cytokinins $-0.5 \mathrm{~mL} / \mathrm{min}$. Unlabeled IAA, ABA, GA3, trans-zeatin-O-glucoside ( $\mathrm{t}-\mathrm{ZG})$, trans-zeatin ( $\mathrm{t}-\mathrm{Z}$ ), trans-zeatinriboside (t-ZR), isopentenyladenine (iP) isopentenyladenosine (iPA) (SigmaAldrich, USA) were used as standards in the construction of calibration tables.

The content of analytes in the samples was monitored using a mass spectrometer in the combined mode (electrospray and chemical ionization at atmospheric pressure) with negative polarity of ionization of analyte molecules during analysis of IAA, GA3, ABA and positive during analysis of cytokinins (CK). For quantitative analysis of GA3 the signal of the mass detector MSD SIM (setting 50\% of the scan time of the detector indicator mass of the ionized molecule/charge 345) was used. If the content of phytohormone was less than $2.01 \mathrm{ng} / \mathrm{g}$ of crude substance, then in the table this value is indicated as traces.

The experiments were performed in three biological and three analytical replicates. Analysis and calculation of phytohormone content was performed using Agilent OpenLAB CDS ChemStation Edition software (rev. C.01.09).

The results of the investigation were statistically processed using the computer program Statistica 6.0 (StatSoft Inc., USA). One-way analysis of variance was used (differences between mean values were calculated by the ANOVA criterion with Bunferoni correction, they were considered probable at $\mathrm{P}<0.05$ ) (Van Emden, 2008).

\section{Results}

Foliar treatment of sweet pepper in the budding phase with $0.005 \%$ aqueous solution of GA3 and $0.025 \%$ aqueous solution of EW- 250 affected the rate of growth processes. During the growing season, the height of the shoots was dominated by plants treated with GA3 solution, while under the action of the retardant in the first half of the growing season the growth of plants did not differ to a great extent from the control sample, and in the second it slowed down. In the fruit formation phase, the linear sizes of plants treated with GA3 exceeded the control sample by $33.1 \%$, while under the action of EW-250 they were $8.9 \%$ lower than the control sample (Fig. 1). Since the main donor of plastic substances in the plant is a leaf, we made an analysis of the effect of growth regulators on the leaf apparatus. It turned out that after treatment with solutions of GA3 and EW-250, the number of leaves on the plant increased by $25.9 \%$ and $18.6 \%$, respectively (Fig. 2).

Under the action of growth regulators, the mass of raw matter of leaves increased. Under the influence of GA3, this figure increased by $2.7 \pm$ $0.09 \mathrm{~g}$ per plant, while after treatment with a retardant - only $1.3 \pm 0.06 \mathrm{~g}$ (Table 1). Both growth regulators increased the crude weight of stems and roots. During GA3 treatment, the mass of the stem increased by $10.7 \pm$ $0.36 \mathrm{~g}$, and the weight of the root - by $1.8 \pm 0.07 \mathrm{~g}$. Under the influence of EW-250, the weight of the stem exceeded the control value by $2.6 \pm$ $0.08 \mathrm{~g}$, and the mass of the root $-0.49 \pm 0.05 \mathrm{~g}$ (Table 1). Growth regulators also affected the accumulation of dry matter of the whole plant. In the phase of fruit formation GA3 induced an increase in dry weight by $4.2 \pm$ $0.12 \mathrm{~g}$, and EW-250 - by $1.6 \pm 0.06 \mathrm{~g}$ (Table 1 ).

The area of leaves on the plant is one of the main indicators that affect the crop yield. It is found that during the whole period of research the area of leaf blades after treatment of plants with GA3 and antigibberellin increased. Treatment with the phytohormone and retardant led to a rise in leaf area during carpogenesis by 16.4 and $11.6 \mathrm{~cm}^{2}$, respectively (Fig. 3), 
at the end of the experimental period, the leaf surface area increased by $35.8 \%$ and $21.5 \%$, respectively (Fig. 4). Under the action of growth regulators the number of flowers on the plant also rose.

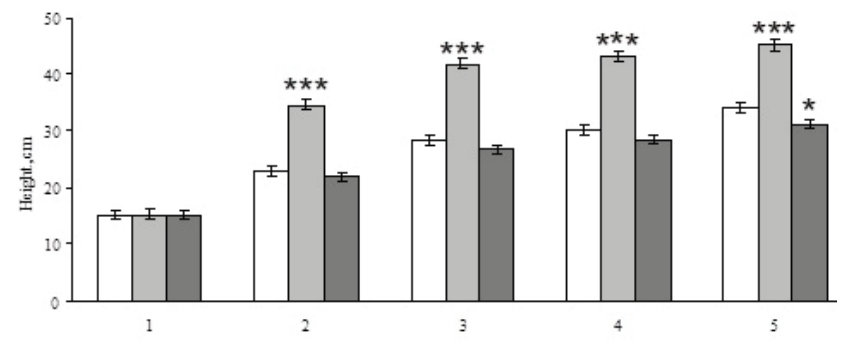

Fig. 1. Effect of foliar treatment with gibberellic acid and tebuconazole solutions on the height of Capsicum annum $\mathrm{L}$. cv. Antey: treatment in budding phase; $\mathrm{n}=10 ; \mathrm{x} \pm \mathrm{SE}$; white - control, light grey $0.005 \%$ gibberellic acid, dark grey $-0.025 \%$ tebuconazole; differences between the mean values were calculated using the Bonferoni-corrected ANOVA criterion, considered to be significant at * $-\mathrm{P}<0.05$; ** $-\mathrm{P}<$ $0.01 ; * * *-\mathrm{P}<0.001$ compared to control at this stage of vegetation; 1 - date of processing, $2-10$ th, $3-20$ th, $4-30$ th, $5-40$ th day after processing

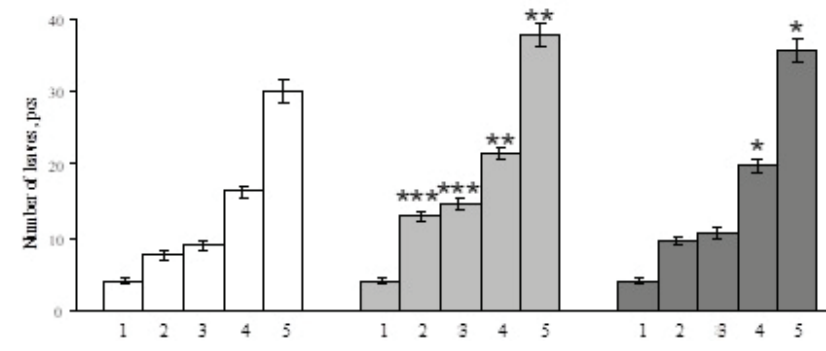

Fig. 2. Effect of foliar treatment with gibberellic acid and tebuconazole solutions on the number of leaves on Capsicum annuum L. cv. Antey: treatment in budding phase; $\mathrm{n}=10, \mathrm{x} \pm \mathrm{SE}$; white - control, light grey $0.005 \%$ gibberellic acid, dark grey $-0.025 \%$ tebuconazole; differences between the mean values were calculated using the Bonferroni-corrected

ANOVA criterion, considered to be significant at ${ }^{*}-\mathrm{P}<0.05$

$* *-\mathrm{P}<0.01 ; * * *-\mathrm{P}<0.001$ compared to control at this stage of vegetation; 1 - date of processing, $2-10$ th,

$3-20$ th, $4-30$ th, $5-40$ th day after processing

Table 1

Influence of foliar treatment with solutions of gibberellic acid and tebuconazole on the mass of vegetative organs of Capsicum annuum L. cv. Antey $(\mathrm{n}=10, \mathrm{x} \pm \mathrm{SE})$

\begin{tabular}{lrrc}
\hline \multicolumn{1}{c}{ Parameter } & \multicolumn{1}{c}{$\begin{array}{c}\text { Control } \\
\text { sample }\end{array}$} & \multicolumn{1}{c}{$\begin{array}{c}\text { Gibberellic } \\
\text { acid }\end{array}$} & Tebuconazole \\
\hline Mass of leaf raw matter, g & $11.11 \pm 0.32$ & $13.82 \pm 0.41^{*}$ & $12.44 \pm 0.38^{*}$ \\
Mass of stalk raw matter, g & $8.12 \pm 0.25$ & $18.91 \pm 0.61^{* * *}$ & $10.82 \pm 0.33^{* * *}$ \\
Mass of root raw matter, g & $4.10 \pm 0.12$ & $5.93 \pm 0.19^{* * *}$ & $4.63 \pm 0.17^{*}$ \\
$\begin{array}{l}\text { Mass of whole plant raw } \\
\text { matter, g }\end{array}$ & $7.14 \pm 0.23$ & $11.32 \pm 0.35^{* * *}$ & $8.61 \pm 0.29^{* *}$ \\
$\begin{array}{l}\text { Number of flowers on the } \\
\text { plant, pcs. }\end{array}$ & $3.02 \pm 0.12$ & $4.12 \pm 0.18^{* * *}$ & $5.53 \pm 0.27^{* * *}$ \\
\hline
\end{tabular}

Notes: processing of plants is in the budding phase, measurement of indicators is in the fruit formation phase; * $-\mathrm{P}<0.05, * *-\mathrm{P}<0.01, * * *-\mathrm{P}<0.001$, one line was compared by the method of difference between the average values, calculated by the ANOVA criterion with the Bonferroni correction.

Since the content and ratio of photosynthetic pigments are an indicator of the efficiency of the assimilation apparatus, a study of the effect of exogenous treatment with growth regulators on the amount of chlorophyll in the leaves of sweet pepper was conducted. It turned out that under the action of EW-250 the amount of chlorophyll in the leaves during the growing season increased significantly. In the phase of fruit formation, this figure exceeded the control sample by $22.1 \%$. Under the action of GA3, the content of chlorophyll was close to the control sample or dropped by $8-12 \%$ compared with it (Fig. 5).

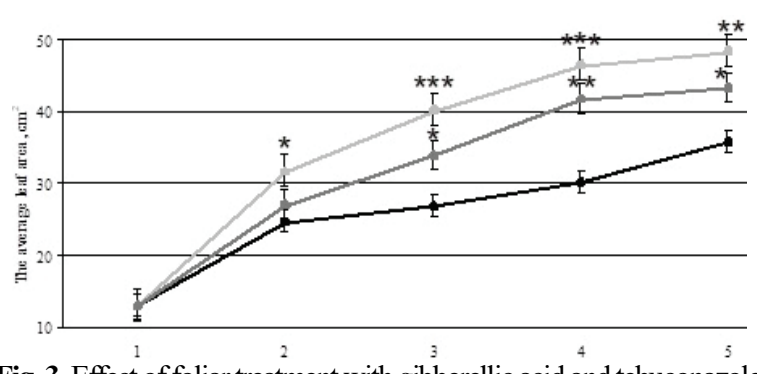

Fig. 3. Effect of foliar treatment with gibberellic acid and tebuconazole solutions on the area of leaf blade of Capsicum annumm L. cv. Antey: treatment in budding phase; $\mathrm{n}=10, \mathrm{x} \pm \mathrm{SE}$; black - control, light grey $0.005 \%$ gibberellic acid, dark grey $-0.025 \%$ tebuconazole; differences between the mean values were calculated using the Bonferroni-corrected ANOVA criterion, considered to be significant at ${ }^{*}-\mathrm{P}<0.05$,

$* *-\mathrm{P}<0.01, * * *-\mathrm{P}<0.001$ compared to control at this stage of vegetation; 1 - date of processing, $2-10$ th, $3-20$ th, $4-30$ th, $5-40$ th day after processing

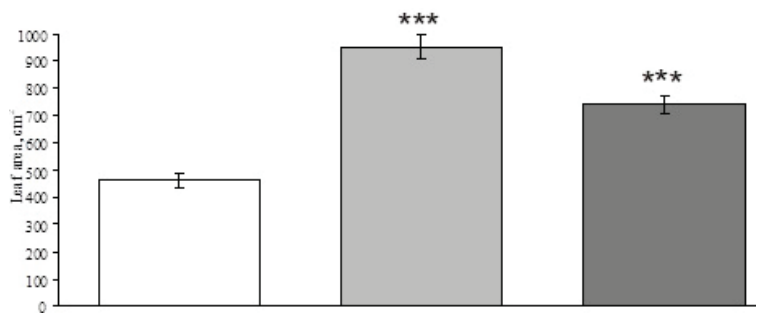

Fig. 4. Effect of foliar treatment with gibberellic acid and tebuconazole solutions on the leaf area of Capsicum annuиm L. cv. Antey: treatment in budding phase; $\mathrm{n}=10, \mathrm{x} \pm \mathrm{SE}$; white - control, light grey $-0.005 \%$ gibberellic acid, dark grey $-0.025 \%$ tebuconazole; differences between the mean values were calculated using the Bonferroni-corrected ANOVA criterion, considered to be significant at ${ }^{*}-\mathrm{P}<0.05$, ** $-\mathrm{P}<0.01$, $* * *-\mathrm{P}<0.001$ compared to the control at this stage of vegetation

The mesostructural organization of the leaf is an important indicator that determines the efficiency of the photosynthetic apparatus of the plant and significantly affects its productivity. It is found that after treatment with EW-250 chlorenchyma thickened by $29.1 \pm 1.65 \mu \mathrm{m}$, and after the use of GA3 - by $11.7 \pm 0.09 \mu \mathrm{m}$. In general, the thickness of the leaf blade after the application of GA3 increased by $14.2 \%$, while after the treatment with EW-250 - by $29.1 \%$. Exogenous GA3 and EW-250 increased columnar parenchyma cell volume by $35.9 \%$ and $77.8 \%$, respectively. However, the size of the spongy parenchyma cells did not change dramatically. The size of the spongy parenchyma cells became bigger with retardant treatments and did not change after the application of GA3 (Table 2).

The effects of foliar treatment of plants with GA3 and EW-250 solutions on the dynamics and distribution of endogenous IAA, GA3 and ABA in sweet pepper organs were studied. Under the action of exogenous GA3 and EW-250 there was a fall in the content of endogenous IAA by $29.6 \%$ and $51.4 \%$ and endogenous ABA by $26.6 \%$ and $51.3 \%$ (Fig. 6 ) in the stems. After treatment with GA3 solution, the content of endogenous GA3 compared to the control sample increased by $50.2 \%$, while EW- 250 induced a decrease of $57.7 \%$. Under GA3 treatment, the accumulation of endogenous GA3 (almost doubled) and IAA ( 0.8 times) increased, and ABA decreased ( 0.6 times). Under the action of the retardant, the ABA content did not change and GA3 as well as IAA decreased by $96 \%$ and $42.0 \%$, respectively.

Growth regulators also affected the content of various forms of cytokinins in the aboveground vegetative organs of sweet pepper. Under control conditions, five forms of cytokinins were identified in leaves and stems: zeatin (Z), zeatinribozid (ZR), zeatin-O-glucoside (ZG), isopentenyladenine (iP), isopentenyladenosine (iPA, Table 3). GA3 and EW-250 induced a fall in the cytokinin pool in stems by $51.4 \%$ and $69.5 \%$, respectively, while in leaves an increase of $14.0 \%$ and $35.5 \%$ is observed. When using GA3, the content of cytokinins enlarged due to the accumulation of $\mathrm{ZG}, \mathrm{Z}$ and $\mathrm{ZR}$, while under the action of the retardant, such an increase occurred exclusively due to iP. 
Table 2

Influence of foliar treatment with solutions of gibberellic acid and tebuconazole on mesostructural parameters of leaves of Capsicum annuum L. cv. Antey $(\mathrm{n}=35, \mathrm{x} \pm \mathrm{SE})$

\begin{tabular}{lccc}
\hline \multicolumn{1}{c}{ Parameter } & Control sample & Gibberellic acid & Tebuconazole \\
\hline Leaf blade thickness, $\mu \mathrm{m}$ & $140.2 \pm 2.4$ & $160.1 \pm 1.9^{* * *}$ & $181.0 \pm 4.5^{* * *}$ \\
Upper epidermis thickness, $\mu \mathrm{m}$ & $17.91 \pm 0.57$ & $25.52 \pm 0.29^{* * *}$ & $28.51 \pm 0.89^{* * *}$ \\
Chlorenchyma thickness, $\mu \mathrm{m}$ & $107.4 \pm 1.2$ & $119.1 \pm 1.3^{* * *}$ & $136.6 \pm 2.8^{* * *}$ \\
Lower epidermis thickness, $\mu \mathrm{m}$ & $14.92 \pm 0.61$ & $15.53 \pm 0.39$ & $15.93 \pm 0.77$ \\
Columnar parenchyma cell volume, $\mu \mathrm{m}^{3}$ & $8603 \pm 317$ & $11691 \pm 432^{* * *}$ & $15297 \pm 754^{* * *}$ \\
Spongy parenchyma cell length, $\mu \mathrm{m}$ & $25.93 \pm 0.42$ & $26.42 \pm 0.44$ & $31.44 \pm 0.83^{* * *}$ \\
Spongy parenchyma cell width, $\mu \mathrm{m}$ & $23.12 \pm 0.57$ & $24.32 \pm 0.37$ & $30.03 \pm 0.73^{* * *}$ \\
\hline
\end{tabular}

Note: processing of plants is in the budding phase, measurement of indicators is in the phase of beginning of fruit formation; ${ }_{-}-\mathrm{P}<0.05,{ }^{*} *_{-} \mathrm{P}<0.01, *_{*} *_{-} \mathrm{P}<0.001$, one line was compared by the method of difference between the average values, calculated by the ANOVA criterion with the Bonferroni correction.

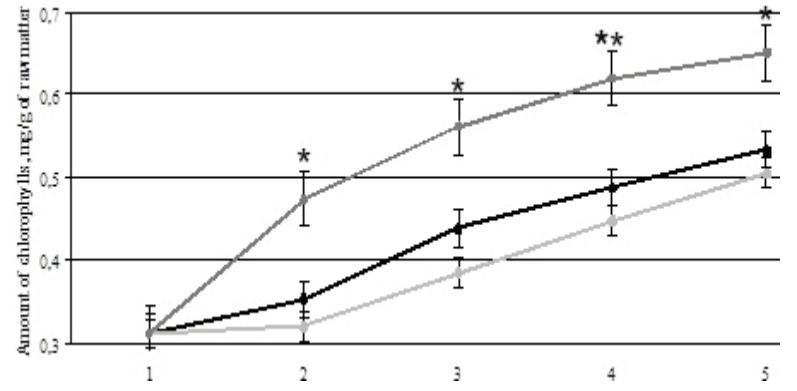

Fig. 5. Effect of foliar treatment with gibberellic acid and tebuconazole solutions on content of chlorophylls $(a+b)$ in leaves of Capsicum annuиm L. cv. Antey: processing in the budding phase; $\mathrm{n}=5 ; \mathrm{x} \pm \mathrm{SE}$; black - control, light grey $-0.005 \%$ gibberellic acid, dark grey $-0.025 \%$ tebuconazole; differences between the mean values were calculated using the Bonferroni-corrected ANOVA criterion, considered to be significant at ${ }^{*}-\mathrm{P}<0.05 ; * *-\mathrm{P}<0.01 ; * * *-\mathrm{P}<0.001$ compared to control at this stage of vegetation; 1 -date of processing, $2-10$ th, $3-20$ th, $4-30$ th, $5-40$ th day after processing

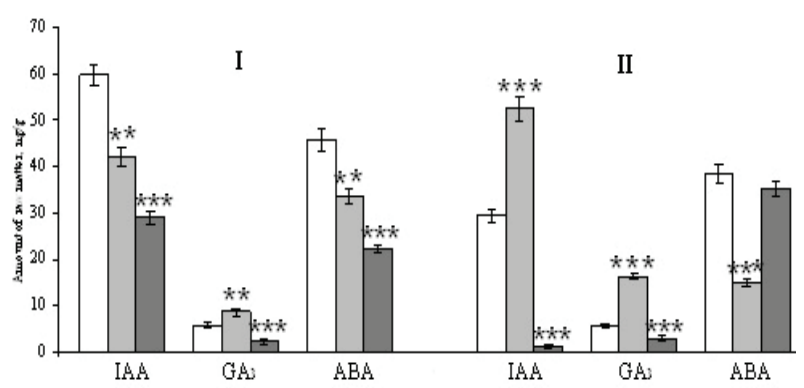

Fig. 6. Effect of foliar treatment with gibberellic acid and tebuconazole solutions on the content of endogenous phytohormones in stems and leaves of Capsicum annum L. cv. Antey: treatment in budding phase; $\mathrm{n}=6 ; \mathrm{x} \pm \mathrm{SE}$; white - control, light grey $-0.005 \%$ gibberellic acid, dark grey $-0.025 \%$ tebuconazole; $a$-the stem; $b$-the leaves; differences between the mean values were calculated using the Bonferroni-corrected

ANOVA criterion, considered to be significant at $*-\mathrm{P}<0.05$,

$$
* *-\mathrm{P}<0.01,{ }^{* * *}-\mathrm{P}<0.001
$$

The results of our studies revealed a positive effect of growth regulators on the productivity of the sweet peppers. Thus, after foliar treatment with GA3 and EW-250 solutions, the number of fruits on pepper plants increased by $58.1 \%$ and $18.6 \%$, respectively (Table 4 ). There was a rise in the diameter and length of the fruit under the action of the retardant and a decrease or absence of such changes after the use of growth stimulant. The average weight of one fruit under the action of GA3 decreased by $24.8 \%$ and increased after treatment with EW- 250 by $29.5 \%$. The change in the quantitative indicators of the elements of productivity under the action of growth regulators led to an improvement in the biological productivity of the crop. The most significant yield of fruit from the plant rose after the application of EW-250 and was $99.3 \pm 3.99 \mathrm{~g}$ per plant. When treated with a solution of GA3, this figure increased to $35.0 \pm 1.09 \mathrm{~g}$ per plant (Table 4).

\section{Discussion}

One of the fundamental tasks of modern phytophysiology is the study of the mechanisms of hormonal regulation of plant growth and development. With the participation of endogenous phytohormones, physiological and biochemical processes in cells, tissues and organs are controlled, and the growth and development of the whole plant is regulated. The change in the rate of growth processes under the action of exogenous growth regulators, in particular gibberellin-like compounds, is due to changes in the balance of endogenous phytohormones (Rademacher, 2016). Therefore, the study of the effect of gibberellins and antigibberellic preparations on the growth, development and productivity of cultivated plants deserves special attention (Jabir et al., 2017). Activation of growth processes and changes in the balance of endogenous hormones under the influence of exogenous gibberellins was observed in the organs of flax plants (Kim et al., 2018), lilies (Ahmad et al., 2019), radish (Jabir et al., 2017) and rapeseed (Zuo et al., 2020).

\section{Table 3}

Influence of gibberellic acid and tebuconazole on the content of cytokinin isoforms in stems and leaves of Capsicum annuum L. cv. Antey, ng/g of raw material; treatment of plants is in the budding phase, measurement of indicators is in the phase of the beginning of fruit formation $(n=6, x \pm S E)$

\begin{tabular}{|c|c|c|c|c|}
\hline Part & Parameter & Control sample & $\begin{array}{c}\text { Gibberellic } \\
\text { acid }\end{array}$ & Tebuconazole \\
\hline \multirow{6}{*}{ Stem } & Zeatin & $4.81 \pm 0.22$ & $29.92 \pm 1.48^{*}$ & $6.83 \pm 0.32 * *$ \\
\hline & Zeatinribozid & $159.4 \pm 7.7$ & traces & $55.2 \pm 2.4^{* * *}$ \\
\hline & Zeatin-O-Glucoside & $58.82 \pm 2.91$ & $64.44 \pm 3.03$ & traces \\
\hline & Isopentenyladenine & traces & traces & traces \\
\hline & Isopentenyladenosine & $49.63 \pm 2.44$ & $38.12 \pm 1.88^{*}$ & $21.11 \pm 1.01^{* * *}$ \\
\hline & Amount of cytokinins & $272.6 \pm$ & $132.4 \pm 6.4^{*}$ & $83.1 \pm 1.3 * * *$ \\
\hline \multirow{6}{*}{ Leaf } & Zeatin & $109.5 \pm 5.2$ & $82.4 \pm 4.0^{*}$ & $36.2 \pm 1.8^{* * *}$ \\
\hline & Zeatinribozid & $74.6 \pm 3.7$ & $129.9 \pm 6.3^{*}$ & $54.3 \pm 2.7^{* *}$ \\
\hline & Zeatin- $O$-Glucoside & $212.6 \pm 32.3$ & $265.8 \pm 28.1^{*}$ & $49.1 \pm 2.4 * * *$ \\
\hline & Isopentenyladenine & & $3.3 \pm 0.1^{*}$ & $408.3 \pm 19.9^{* * *}$ \\
\hline & Isopentenyladenosine & $27.93 \pm 1.38$ & $2.12 \pm 0.09^{*}$ & $27.43 \pm 1.31$ \\
\hline & Amount of cytokinins & $424.5 \pm 42.6$ & $483.6 \pm 38.7$ & $575.3 \pm 28.2^{* *}$ \\
\hline
\end{tabular}

Note: ${ }^{*}-\mathrm{P}<0.05, * *-\mathrm{P}<0.01, * * *-\mathrm{P}<0,001$, one line was compared by the difference between the mean values calculated by the ANOVA criterion with the Bonferroni correction.

\section{Table 4}

The effect of gibberellic acid and tebuconazole on the productivity elements of Capsicum annuum L. cv. Antey $(\mathrm{n}=10, \mathrm{x} \pm \mathrm{SE})$

\begin{tabular}{lccc}
\hline \multicolumn{1}{c}{ Parameter } & Control sample & $\begin{array}{c}\text { Gibberellic } \\
\text { acid }\end{array}$ & Tebuconazole \\
\hline Fruit length, cm & $4.11 \pm 0.19$ & $4.31 \pm 0.21$ & $6.12 \pm 0.32^{* * *}$ \\
Fruit diameter, cm & $4.04 \pm 0.18$ & $3.42 \pm 0.15^{*}$ & $5.01 \pm 0.24^{*}$ \\
Average fruit weight, g & $43.1 \pm 2.1$ & $32.4 \pm 1.3^{* *}$ & $55.8 \pm 2.7^{* *}$ \\
Number of fruits per plant, pcs. & $4.33 \pm 0.14$ & $6.83 \pm$ & $5.11 \pm 0.16^{* *}$ \\
& & $0.18^{* * *}$ & \\
Mass of fruit from one plant, g & $185.3 \pm 8.9$ & $220.3 \pm 9.8^{*}$ & $284.6 \pm 12.9^{* * *}$ \\
\hline
\end{tabular}

Note: processing of plants is in the budding phase, measurement of indicators is in the phase of fruit ripening; $*-\mathrm{P}<0.05, * *-\mathrm{P}<0.01$, *** $-\mathrm{P}<0.001$, one line was compared by the difference between the mean values calculated by the ANOVA criterion with the Bonferroni correction. 
It is found that the use of exogenous GA3 and anti-gibberellin triazole derivative EW-250 led to crucial changes in the growth rate of pepper plants. In our previous study on eggplant culture, similar results were obtained (Rogach et al., 2020). The increase in the linear size of the shoots of GA3-treated plants and the raw biomass of roots, stems and leaves correlated with the increase in the content of endogenous GA3 in the stems and GA3 and IAA in the leaves. Changes in the status of endogenous phytohormones after treatment with exogenous gibberellins have been reported in the works of other authors conducted on sugar cane plants (Qiu et al., 2019), cucumbers (Ullah et al., 2011) and camellia (Wen et al., 2018). We showed that under the action of EW-250 the content of GA3 and IAA in the stems and leaves of pepper decreased, and the content of $\mathrm{ABA}$ in the leaves increased against the background of inhibited stem growth and increased mass of crude matter of all vegetative organs. The obtained data complement our results of anatomical-morphological and physiological-biochemical studies of eggplant plants (Rogach et al., 2020) as well as the work of other authors on the effects of triazolederived retardants of paclobutrazole shown for magnolia plants (Shi et al., 2021), uniconazole - for winter barley plants (Bakheta \& Hussein, 2014) and hexaconazole - for cucumber plants (Tae-Yun \& Jung-Hee, 2012).

It is found out that a relatively low content of gibberellins in the control and experimental variants was observed against the background of a sufficiently high level of $\mathrm{ABA}$ in the stems and leaves of pepper. The important role of ABA in growth and shaping processes is indicated in other sources (Kosakivska et al., 2021). Under the action of exogenous $\mathrm{GA} 3$ and EW-250, the content of ABA in the leaves and stems of pepper increased. Kang et al. (2014) and Kim et al. (2018) reported similar changes in the hormonal status of soybean and flax plants.

It is established that exogenous GA3 enhanced the growth and formation processes of soybean and sugar cane plants (Kang et al., 2014; Qiu et al., 2019). Under the action of the retardant, the growth of soybean stems was inhibited (Kim et al., 2018), but branching was intensified and more leaves were laid in Magnolia wufengensis plants (Shi et al., 2021). As a result of slowing down the linear growth of the stem, plastic substances were directed to the formation of new leaves in cucumber plants (Tae-Yun \& Jung-Hee, 2012).

Chlorophyll synthesis is regulated by the participation of cytokinin group phytohormones (Rogach et al., 2020). It is shown that under the action of antigibberellin EW-250, in contrast to GA3, the chlorophyll content was boosted. The results obtained are consistent with the nature of the accumulation of cytokinins in the leaves of plants treated with the retardant. Under the action of the retardant, the pool of cytokinins significantly exceeded the control values, while after the application of GA3 it did not change. The rise in the content of chlorophyll and cytokinin hormones under the influence of antigibberellic preparations is mentioned by other authors (Liu et al., 2015).

Anatomical-morphological and physiological-biochemical changes under the action of growth regulators were realized through the restructuring of donor-acceptor relations and redistribution of flows of plastic substances between vegetative and generative organs (Poprotska et al., 2019). Treatment with exogenous GA3 and EW-250 induced the formation of a more powerful leaf apparatus, increasing the number of leaves, their weight and area. The enlargement of photosynthetic activity enhanced the donor function of the leaf, and the increase in the number of generative organs intensified the acceptance of newly formed plastic substances, which ultimately increased the productivity of the culture.

Thus, the use of exogenous multi-vector growth regulators - GA3 and EW-250 in soil-sandy culture changed the growth rate of pepper plants, affected the number of leaves on the plant, the weight of their raw material, leaf surface area and mesostructure of leaves, chlorophyll content, endogenous balance phytohormones in aboveground vegetative organs, which contributed to the increase of biological productivity of the crop.

\section{Conclusions}

Exogenous plant growth regulators with different directions of action GA3 (native stimulant hormone) and EW-250 (triazole derivative retardant), modulating the dynamics and distribution of endogenous plant phytohormones Capsicum annum $\mathrm{L}$. of Antey variety, induced changes in morphogenesis, structure and function and enhanced the productivity of culture.

It is found that foliar treatment of GA3 increased plant height, while EW-250 inhibited stem elongation. Both regulators stimulated the formation of new leaves, the accumulation of their biomass, increasing the area of a single leaf blade and the area of leaves on the plant. The biomass of stems and roots and the mass of dry matter of the whole plant also increased under the action of the preparations. EW-250 increased the amount of chlorophyll $(a+b)$ in the leaves. Both regulators induced thickening of leaf blades due to the growth of chlorenchyma cells. At the same time, there was an increase in the volume of cells of the columnar parenchyma. However, the use of EW-250 turned out to be more effective.

After treatment with exogenous GA3, the content of endogenous IAA and ABA decreased and GA3 in plant stems was boosted. Instead, EW-250 caused a decrease in the levels of GA3, IAA and ABA in the stems. Exogenous GA3 enhanced the accumulation of endogenous GA3 and IAA and inhibited ABA in the leaves. Under the action of the retardant, the level of ABA in the leaves did not change, while GA3 and IAA decreased. Treatment of plants with the studied growth regulators caused a decrease in the pool of cytokinins (CK) in the stems. The EW-250 showed a considerable increase in CK content in the leaves. After spraying with GA3 solution, the level of ZG, Z and ZR rose. Under the action of the retardant, the increase in the $C K$ pool occurred exclusively due to the iP.

Thus, anatomical-morphological and structural-functional rearrangements in pepper plants under the action of GA3 and EW-250 are due to changes in the balance and distribution of endogenous hormones. Increased photosynthetic activity, stimulation of growth processes of some plant organs and inhibition of others enlarged biological productivity of the culture. The obtained results give a new practical approach to improving the yield of sweet pepper. At the same time, some questions about the molecular and physiological mechanisms of influence of the studied growth regulators require further study.

\section{References}

Ahmad, I., Kamran, M., Meng, X., Ali, S., Bilegjargal, B., Cai, T., Liu, T., \& Han, Q. (2019). Effects of plant growth regulators on seed filling, endogenous hormone contents and maize production in semiarid regions. Joumal of Plant Growth Regulation, 38(4), 1467-1480.

Bakheta, M. A., \& Hussein, M. M. (2014). Uniconazole effect on endogenous hormones, proteins and proline contents of barley plants (Hordeum vulgare) under salinity stress (NaCl). Nusantara Bioscience, 6(1), 39- 44

Cavalcante, Í. H. L., Nogueira e Silva, G. J., Cavacini, J. A., Araújo e Amariz, R., Tonetto de Freitas, S., Oliveira de Sousa, K. Â., Almeida da Silva, M., \& Gomes da Cunha, J. (2020). Metconazole on inhibition of gibberellin biosynthesis and flowering management in mango. Erwerbs-Obstbau, 62(1), 89-95.

Jabir, B. M. O., Kinuthia, K. B., Faroug, M. A., Awad, F. N., Everlyne, M. M., Ahmadzai, Z., \& Liu, L. (2017). Effects of gibberellin and gibberellin biosynthesis inhibitor (paclobutrazol) applications on radish (Raphanus sativus L.) taproot expansion and the presence of authentic hormones. International Journal of Agriculture and Biology, 19(4), 779-786.

Kang, S.-M., Radhakrishnan, R., Khan, A. L., Kim, M.-J., Park, J.-M., Kim, B.-R. Shin, D.-H., \& Lee, I.-J. (2014). Gibberellin secreting rhizobacterium, Pseudomonas putida $\mathrm{H}-2-3$ modulates the hormonal and stress physiology of soybean to improve the plant growth under saline and drought conditions. Plant Physiology and Biochemistry, 84, 115-124.

Khodanitska, O. O., Kuryata, V. G., Shevchuk, O. A., Tkachuk, O. O., Poprotska, I. V. (2019). Effect of treptolem on morphogenesis and productivity of linseed plants. Ukrainian Joumal of Ecology, 9(2), 119-126.

Kim, S.-K., Han, C.-M., Shin, J.-H., \& Kwon, T.-Y. (2018). Effects of paclobutrazol and prohexadione-ca on seed yield, and content of oils and gibberellin in flax grown in a greenhouse. Korean Journal of Crop Science, 63(3), 265-271.

Kosakivska, I. V., Vasyuk, V. A., Voytenko, L. V., Shcherbatiuk, M. M., Romanenko, K. O., \& Babenko, L. M. (2020). Endogenous phytohormones of fern Polystichum aculeatum (L.) Roth gametophytes at different stages of morphogenesis in vitro culture. Cytology and Genetics, 54(1), 23-30.

Kozak, V. M., Romanenko, E. R., \& Brygadyrenko, V. V. (2020). Influence of herbicides, insecticides and fungicides on food consumption and body weight of Rossiulus kessleri (Diplopoda, Julidae). Biosystems Diversity, 28(3), 272-280.

Latimer, G. W. (Ed.). (2012). Official methods of analysis of AOAC International. 19th edition. AOAC International, Gaithersburg.

Lieshchova, M. A., Tishkina, N. M., Bohomaz, A. A., Gavrilin, P. M., \& Brygadyrenko, V. V. (2018). Combined effect of glyphosphate, saccharin and sodium benzoate on rats. Regulatory Mechanisms in Biosystems, 9(4), 591-597. 
Liu, Y., Fang, Y., Huang, M., Jin, Y., Sun, J., Tao, X., Zhang, G., He, K., Zhao, Y., \& Zhao, H. (2015). Uniconazole-induced starch accumulation in the bioenergy crop duckweed (Landoltia punctata) I: Transcriptome analysis of the effects of uniconazole on chlorophyll and endogenous hormone biosynthesis. Biotechnology for Biofuels, $8,57$.

Muhammad, I., \& Muhammad, A. (2013). Gibberellic acid mediated induction of salt tolerance in wheat plants: Growth, ionic partitioning, photosynthesis, yield and hormonal homeostasis. Environmental and Experimental Botany, 86, 76-85.

Polyvanyi, S. V., Golunova, L. A., Baiurko, N. V., Khodanitska, O. O., Shevchuk, V. V., Rogach, T. I., Tkachuk, O. O., Zavalnyuk, O. L., \& Shevchuk, O. A. (2020). Morphogenesis of mustard white under the action of the antigibberellic preparation chlormequat chloride. Modem Phytomorphology, 14, 101-103.

Poprotska, I., Kuryata, V., Khodanitska, O., Polyvanyi, S., \& Golunova, L. (2019). Effect of gibberellin and retardants on the germination of seeds with different types of reserve substances under the conditions of skoto- and photomorphogenesis. Biologija, 65(4), 296-307.

Qiu, L. H., Chen, R. F., Luo, H. M., Fan, Y. G., Huang, X., Liu, J. X., Xiong, F. Q., Zhou, H. W., Gan, C. K., Wu, J. M., \& Li, Y. R. (2019). Effects of exogenous GA3 and DPC treatments on levels of endogenous hormone and expression of key gibberellin biosynthesis pathway genes during stem elongation in sugarcane. Sugar Tech, 21, 936-948.

Rademacher, W. (2016). Chemical regulators of gibberellin status and their application in plant production. Annual Plant Reviews, 49, 359-403.

Ribeiro, D. M., Araújo, W. L., Fernie, A. R., Schippers, J. H. M., \& Mueller-Roeber, B. (2012). Translatome and metabolome effects triggered by gibberellins during rosette growth in Arabidopsis. Journal of Experimental Botany, 63(7), 2769 2786.

Rogach, V. V., Voitenko, L. V., Shcherbatiuk, M. M., Kosakivska, I. V., \& Rogach, T. I. (2020). Morphogenesis, pigment content, phytohormones and productivity of eggplants under the action of gibberellin and tebuconazole. Regulatory Mechanisms in Biosystems, 11(1), 129-135.

Rohach, V. V. (2017). Vplyv stymuljatoriv rostu na fotosyntetychnyj aparat, morfogenez i produkcyjnyj proces baklazhana (Solanum melongena) [Influence of growth stimulants on photosynthetic apparatus, morphogenesis and production process of eggplant (Solanum melongena)]. Biosystems Diversity, 25(4), 297 304 (in Ukrainian).

Rohach, V. V., Rohach, T. I., Kylivnyk, A. M., Polyvanyi, S. V., Bayurko, N. V., Nikitchenko, L. O., Tkachuk, O. O., Shevchuk, O. A., Hudzevych, L. S., \& Levchuk, N. V. (2020). The influence of synthetic growth promoters on morphophysiological characteristics and biological productivity of potato culture. Modern Phytomorphology, 14, 111-114.
Shevchuk, O. A., Tkachuk, O. O., Kuryata, V. G., Khodanitska, O. O., \& Polyvanyi, S. V. (2019). Features of leaf photosynthetic apparatus of sugar beet under retardants treatment. Ukrainian Journal of Ecology, 9(1), 115-120.

Shevchuk, O. A., Kravets, O. O., Shevchuk, V. V., Khodanitska, O. O., Tkachuk O. O., Golunova, L. A., Polyvanyi, S. V., Knyazyuk, O. V., \& Zavalnyuk, O. L. (2020). Features of leaf mesostructure organization under plant growth regulators treatment on broad bean plants. Modern Phytomorphology, 14, 104-106.

Shi, X., Chen, S., \& Jia, Z. (2021). The dwarfing effects of different plant growth retardants on Magnolia wufengensis L. Y. Ma et L. R. Wang. Forests, 12(1), 19.

Soumya, P. R., Kumar, P., \& Pal, M. (2017). Paclobutrazol: A novel plant growth regulator and multi-stress ameliorant. Indian Joumal of Plant Physiology, 22, 267-278.

Sugiura, D., Sawakami, K., Kojim, M., Sakakibara, H., Terashima, I., \& Tateno, M. (2015). Roles of gibberellins and cytokinins in regulation of morphological and physiological traits in Polygonum cuspidatum responding to light and nitrogen availabilities. Functional Plant Biology, 42(4), 397-409.

Tae-Yun, K, \& Jung-Hee, H. (2012). Effects of hexaconazole on growth and antioxidant potential of cucumber seedlings under UV-B radiation. Environmental Sciences, 21(12), 1435-1447.

Ullah, H., Bano, A., Khokhar, K. M., \& Mahmood, T. (2011). Effect of seed soaking treatment with growth regulators on phytohormone level and sex modification in cucumber (Cucumis sativus L.). African Journal of Plant Science, 5(10), 599-608.

Upreti, K. K., Reddy, Y. T. N., Shivu Prasad, S. R., Bindu, G. V., Jayaram, H. L., \& Rajan, S. (2013). Hormonal changes in response to paclobutrazol induced early flowering in mango cv. Totapuri. Scientia Horticulturae, 150, 414418.

Van Emden, H. F. (2008). Statistics for terrified biologists. Blackwell, Oxford.

Wen, Y., Su, S. C., Ma, L. Y., \& Wang, X. N. (2018). Effects of gibberellic acid on photosynthesis and endogenous hormones of Camellia oleifera Abel. in 1st and 6th leaves. Joumal of Forest Research, 23(5), 309-317.

Yu, S. M., Lo, S. F., \& Ho, T. D. (2015). Source-sink communication: Regulated by hormone, nutrient, and stress cross-signaling. Trends in Plant Science, 20(12), $844-857$.

Zheng, R., Wu, Y., \& Xia, Y. (2012). Chlorocholine chloride and paclobutrazol treatments promote carbohydrate accumulation in bulbs of Lilium Oriental hybrids 'Sorbonne'. Journal of Zhejiang University, Science B, Biomedicine and Biotechnology, 13(2), 136-144.

Zuo, Q., Wang, L., Zheng, J., You, J., Yang, G., Leng, S., \& Liu, J. (2020). Effects of uniconazole rate on agronomic traits and physiological indexes of rapeseed blanket seedling. Oil Crop Science, 5(4), 198-204. 